\title{
Elementary School Teachers' Perceptions on Bilingualism of School-age Multicultural Children for Collaboration between Educational Environment and Speech-Language Pathology
}

\author{
MinJi Jung, Sangshim Hwang \\ Department of Speech-Language Pathology, Nambu University, Gwangju, Korea
}

\author{
Correspondence: Sangshim Hwang, PhD \\ Department of Speech-Language Pathology, \\ Nambu University, 23 Cheomdanjungang-ro, \\ Gwangsan-gu, Gwangju 62271, Korea \\ Tel: +82-62-970-0214 \\ Fax: +82-62-970-0076 \\ E-mail: hss2008@nambu.ac.kr
}

Received: October 20, 2019

Revised: November 6, 2019

Accepted: November 6, 2019

This work is based on a partial data from the first author's masters's thesis.

This work was supported by Nambu University Research Fund 2019.

\begin{abstract}
Objectives: The purpose of this study was to examine elementary school teachers' experience and perceptions regarding bilingual language use of children in multicultural families. Methods: An initial questionnaire was formed through analysis of previous research and an interview with a teacher group. After the preliminary experiments, a final questionnaire was completed. The questionnaire was distributed to teachers in the Jeonrabuk-do region. One hundred eighty-nine questionnaires were collected and the results were analyzed through frequency and chi-square tests. Results: The $57.5 \%$ of teachers attended multicultural classes and there was a high demand for teacher education on school life problems and language development. The $20.4 \%$ of multicultural children spoke two languages, and $31.2 \%$ of teachers recommended bilingual language use. The main reasons for this recommendation were identity and self-stability, and the reasons for not recommending bilingual language use were academic problems and a delay in learning Korean. Teachers were generally positive about bilingualism, but most teachers thought that they should learn Korean first. The necessity of bilingual education was also positive, and they thought bilingual education was provided by parents, language development supporters, and speech language therapists. The bilingual learning period was in the order of kindergarten, birth, and elementary school. When examining the difference of perception according to background variables, there were statistical differences according to working area for bilingual learning, and age and career for bilingual education. Conclusion: Teachers' perception of bilingualism was positive, but they were urgently considering problems such as academic achievement, school life adjustments, and Korean language acquisition. In the field of speech language pathology, it is necessary to reconsider the role of speech language pathology in the field of education in relation to language acquisition including bilingual language acquisition.
\end{abstract}

Keywords: Bilingual, School age multicultural children, Elementary school teacher, Collaboration, Speech language pathology
최근 영유아기 다문화아동의 증가 추세가 둔화된 데 비하여 다 문화학생 인구는 늘어나고 있다. 2018년 다문화학생은 전년 대비 $11.7 \%$ 증가한 12 만 2 천명으로 전체 학생의 $2 \%$ 대에 진입하였다. 우 리나라 학생수와 학령인구는 감소 추세인 반면 다문화학생은 최근 6년간 매년 1만 명 이상 증가하였다. 이 중 초등학생 비중이 $76.1 \%$

\begin{abstract}
로 중학생 $14.8 \%$, 고등학생 $8.7 \%$ 에 비교할 때 가파른 증가를 하고 있다(Statistics Korea, 2019). 특히 학령기 다문화아동 중에는 한국 어를 제 2 언어로 습득하는 중도입국 아동이나 노동자 자녀 등도 포 함되어 있기에 교육현장에서 다문화아동들의 학교생활, 한국사회 적응, 정체성, 언어능력 등에 대해 관심과 논의가 지속적으로 이루
\end{abstract}


어지고 있다.

연구에서 학령기 다문화아동들의 심리적인 위축(Lee \& Kwon, 2018), 한국어 능력 부족(Korean Institute Healthy Family [KIHF], 2018; Korean Youth Counselling \& Welfare Institute [KYCI], 2011), 낮은 학업성취(Jung, 2012; KYCI, 2011), 문화적응 스트레스(KYCI, 2011; Shin \& Youn, 2010), 학교생활적응(KYCI, 2011; Tak, Kim, \& Moon, 2014) 등을 염려하는 결과를 보고하고 있다. 이에 따라 이들 의 심리, 정서, 학업, 언어, 문화 등의 어려움을 파악하여 정체성과 자아감 형성에 도움을 주고 학업과 학교생활 적응에 관한 지원 방 안 모색의 필요성을 강조하고 있는데(KYCI, 2011) 그에 대한 하나 의 방안이 이중언어 습득이다. 이는 다문화아동의 정체성, 자아존 중감, 직업선택, 정서적 유대 등과 관련하여 이중언어 습득의 긍정 적인 결과를 여러 연구에서 보고하고 있기 때문이다(Paradis, Genesee, \& Crago, 2011; Wong Fillmore, 1991). 최근 우리나라 교육정 책에서도 이중언어 습득으로 다문화 사회의 잠재력을 최대화하고 국가 인적자원으로서 기반을 마련하며 학교와 사회 적응을 도와 정체성과 소속감을 확고히 할 필요성을 강조하고 있다(Ministry of Education, 2018). 또한 국내연구에서도 다문화아동의 이중언어에 대해 긍정적 영향을 보고하고 있어(Chu \& Choi, 2017) 교육환경에 서 이중언어에 대한 관심과 체계적인 지원의 필요성, 이를 위한 교사 의 역할, 전문가 간의 협력, 교육환경 등의 중요성이 부각되고 있다.

교육환경에서 교사는 학생이나 가족에게 큰 영향을 끼칠 수 있 는 위치에 있다. 교사의 기대가 학생들의 성적에 긍정적인 영향이나 부정적인 영향을 미칠 수 있다는 것은 잘 알려진 사실이다(Babad, Inbar, \& Rosenthal, 1982; Rosenthal \& Jacobson, 1968). 우리나라 다문화아동을 대상으로 한 연구에서도 교사는 다문화아동에게 매우 영향력 있고 교사의 인식이 아동에게 영향을 줄 수 있음을 밝 히고 있다(Bae \& Bong, 2012). 교사의 기대, 신념, 태도 등이 학생들 의 학업성취뿐만 아니라 다문화아동들의 언어사용에도 영향을 주 며(Godley, Sweetland, Wheeler, Minnici, \& Carpenter, 2006), 이에 대한 예는 이중언어에 대한 교사들의 신념에서 살펴볼 수 있다. 이 중언어 습득이 학생들의 인지능력, 문제해결력능력, 상위언어능력, 사고력 등에 긍정적인 영향을 주고, 학업, 직업 선택, 승진의 기회 등에서 잠재적으로 유리하다는 것이 밝혀졌다(Lee, Shetgiri, Barina, Tillitski, \& Flores, 2015; Toppelberg \& Collins, 2010). 그러나 이 러한 잘 입증된 혜택에도 불구하고 교사들은 학생들이 표준언어 나 그 나라의 주언어를 사용하였을 때보다 소수언어나 방언으로 제시하였을 때 더 낮게 평가하거나 기대치가 낮은 경향이 있다 (Crowl \& MacGinitie, 1974). 그러나 전세계적으로 이중언어학습 자 수가 증가하면서 교사들이 이들에게 교육서비스를 제공해야 하
는 현실에 처하게 되면서(Garrity, Aquino-Sterling, Van Liew, \& Day, 2018) 교사들의 신념과 태도가 변화할 필요성이 있음을 지적 하고 있다.

우리나라는 단일언어와 단일문화 중심이었기에 다문화가 익숙 하지 않은 사회였으나 다문화인구 증가와 함께 교육, 보건 등의 분 야에서도 많은 변화가 일어나고 있다. 과거 다문화아동의 언어발달 에 관해서는 한국어 습득을 최우선 과제로 생각하였으나 2015년 이후 정부에서 정책적으로 다문화아동들의 이중언어 습득을 강조 하고 프로그램을 고안하는 등 지원을 하고 있고 다문화부모들도 이중언어 습득에 대한 인식이 변화하고 있다(Hwang, 2018). 그러 나 학교환경에는 이중언어 교육을 위한 인프라가 거의 구축되어 있 지 않으며, 교사들은 다문화아동의 학업성취와 학교생활 적응을 돕는 것만으로도 버거운 상황이다(Jung, 2012; KYCI, 2011). 이와 더불어 결혼이민자 자녀뿐만 아니라 한국어를 제 2 언어로 습득하 는 중도입국 아동이나 노동이주 가족의 자녀들이 입학하는 사례 가 늘고 있어 교사들은 정책과 교육현실 사이에서 어려운 상황에 직면해 있다(Jang \& Jeong, 2012). 이것은 우리나라만의 문제가 아 니며 이러한 상황을 해결을 위한 대안이 관련 분야와의 연계와 협 력이다. 교육환경에서 교사, 교사와 동료, 언어치료사와 같은 보건 전문가 간의 일상적인 협력을 통해 교육서비스의 효율성이 촉진될 수 있기 때문이다(Shaddock, King, \& Giorcelli, 2007).

언어치료사와 교사간 협력의 이점은 아동들의 언어와 의사소통 에 관해 전문가 간의 지식과 기술을 서로 공유할 수 있는 것이다 (Harn, Bradshaw, \& Ogletree, 1999; Kersner, 1996; Tollerfield, 2003; Wright \& Kersner, 2004). 교사와 언어치료사가 접근하는 방식은 다르지만 서로 보완적인 측면이 있기 때문이다. 학령기 아동들의 교육과 관련하여 교사와 언어치료사 모두 더 나은 공동작업, 협업, 교육을 원하는 것으로 나타났으며(Antoniazzi, Snow, \& DicksonSwift, 2010; Dockrell \& Lindsay, 2001; Mroz, 2006; Wright \& Kersner, 1999) 언어치료사가 제2언어를 습득하는 학생들에게 협력적 으로 서비스를 제공하는 것에 동의하고 있다(Kersner, 1996; Wright \& Kersner, 1999). 그러나 교사와 언어치료사는 전문적 역할 차이 로 인해 초점이 다르기 때문에 여러 이점에도 불구하고 서로 협력 이 쉽지 않다. 이에 따라 연구자들은 공동 목표를 향해 노력하면서 직접적인 상호작용의 필요성을 강조하고 있다(Friend \& Cook, 2000). 서로 다른 전공에서 실제적인 협력을 위한 상호작용의 첫 번째 단 계는 협력 분야 전문가들의 인식, 태도 등을 연구하고 의견을 수렴 하여(Lindsay \& Dockrell, 2004; Wright \& Kersner, 2004) 그 결과 를 통해 교육 협력에 적용하는 것이다. 이에 따라 교육, 보건, 의료 등의 각 분야 전문가들의 인식, 태도, 요구 등을 조사하고 그 결과 
를 반영할 것을 권고하고 있다.

앞에서도 언급하였듯이 우리나라도 학령기 인구가 증가하는 상 황에서 사회적 잠재력과 인적자원으로서, 그리고 정체성과 자아감 형성에 도움을 줄 수 있는 방안으로서 이중언어 습득의 필요성을 여러 연구와 국가정책에서 강조하고 있다. 그러나 우리나라는 미국 이나 유럽 등에 비하여 교육환경에서 제 2 언어 습득을 포함한 이중 언어 습득을 위한 실제적인 교육프로그램이 없는 실정이다. 그럼에 도 불구하고 국제결혼, 중도입국, 노동이주, 이민, 난민 등으로 다문 화아동들의 언어습득 형태가 다양해 지면서 교사들은 이러한 학 생들에게 교육 서비스를 제공해야 하는 현실에 처해 있기에 관련 전문가와의 협력이 불가피한 상황이라 할 수 있다. 다문화아동들 의 이중언어 발달을 위해 이중언어코치라는 직업군이 있으나 서비 스 대상연령이 영유아 부모이기에(Ministry of Gender Equality and Family [MOGEF], 2019) 학령기 다문화아동들에게 서비스를 제공하는 것은 언어발달지도사의 역할이라고 할 수 있다(KIHF, 2018). 언어발달지도사는 학령기 다문화아동에게 모국어로서 한 국어 촉진교육, 제 2 언어로서 한국어 습득, 이중언어 습득과 유지를 위한 부모교육과 상담 등을 제공하고 있으며 언어발달지도사 중 $72.3 \%$ 가 이중언어사용 아동에게 한국어 촉진 교육을 제공하고 있 었다(Hwang, 2019). 또한 2018년 이후 언어발달지도사 지원 자격 요건을 언어치료전공으로 제한하고 있다(MOGEF, 2019).

이러한 현실을 볼 때 언어치료전공 언어발달지도사들이 외국의 학교교육에서 다문화아동들에게 제공하고 있는 언어촉진 교육서 비스를 제공하고 있는 셈이다. 따라서 우리나라 초등학생 다문화 아동들의 언어습득과 관련되어 교사와 언어치료사, 또는 언어발달 지도사는 긴밀하게 협력할 수밖에 없는 상황이며 미국을 비롯하여 전세계적으로 다문화인구가 꾸준히 증가하는 상황에서 언어치료 사들이 다양한 문화와 언어를 가진 대상자들의 언어차이, 의사소 통 등에 대하여 민감해야 할 것을 권고하고 있다(Adler, 1990; Terrell \& Hale, 1992). 우리나라는 언어치료사가 학교환경에서 제한된 서비스를 제공하고 있으나 학교언어치료사 활성화의 필요성과 언 어치료사와 교사의 협력적 역할 수행을 통한 연계 필요성을 여러 선행연구에서 제안하고 있으며(Kang \& Park, 2006; Kim, Choi, \& Kim, 2006; Park \& Chang, 2003) 이를 위한 교사들의 인식, 태도 등을 살펴보고 질적이고 효율적인 서비스 제공을 위해 협력 필요성 을 제안하고 있다(Ahn, 2013; Jeong \& Yu, 2009; Lee, 2013). 다문화 아동에 관해서도 학교환경에서 이들의 인구변화 추세와 이중언어 에 대한 대한 인식변화, 정부정책과 교육인프라 등을 볼 때 교육환 경과 언어치료 분야의 협력을 위한 연구가 필요한 시점이 되었다고 본다.
이에 따라 본 연구에서는 우선적으로 학교환경에서 다문화아동 들에게 직접적으로 교육서비스를 제공하는 초등학교 교사를 대상 으로 다문화교육 요구, 이중언어에 대한 인식과 경험 등을 살펴보 고 교육현장과 언어치료사와의 협력 방안 모색을 위한 기초연구를 실시하고자 한다. 구체적인 연구문제는 다음과 같다.

첫째, 초등학교 교사들의 다문화 관련 교육 요구는 어떠한가? 둘째, 초등학교 교사들의 다문화아동 교육 경험은 어떠한가?

셋째, 초등학교 교사들의 이중언어에 관한 인식은 어떠하며, 배 경 변인에 따른 차이는 어떠한가?

\section{연구방법}

\section{연구 참여자}

다문화아동의 이중언어 사용에 대한 초등학교 교사들의 인식, 경험 등을 알아보기 위해서 전라북도 지역 소재 초등학교에 근무 하고 있는 교사 186 명을 대상으로 설문조사를 하였다. 참여자는 남 성이 69명(37.15\%), 여성이 117 명(62.9\%)이었으며, 연령은 30 대가 92 명(49.5\%), 40대 45명(24.2\%), 20대 43명(23.1\%) 등이었다. 근무학교 는 일반 특수통합초등학교가 106명(57\%), 일반초등학교 78명(41.9\%) 등이었다. 학력은 대학졸업이 141 명(75.8\%), 대학원졸은 45 명(24.2\%) 이었다. 경력은 5 년 이상에서 10 년 미만이 56 명(30.1\%), 1년 이상 5 년 미만이 51명(27.4\%) 등이었다. 담당 학년은 5학년이 49명(26.3\%) 으로 가장 많았고 6학년이 45명(24.2\%), 4학년이 32명(17.2\%)이었 으며, 근무지역은 시지역이 120 명(64.5\%), 군지역이 66명(35.5\%)이 었다(Table 1).

\section{연구 도구}

조사를 위한 설문지 개발을 위해서 Hammer, Detwiler, Detwiler, Blood와 Qualls (2004), Hwang (2018), Kwon (2016)의 연구를 근거로 설문 기초 내용을 구성하고 전북지역 초등학교 교사 4 명을 대상으로 집단면담을 실시하였다. 집단면담을 통해 설문 내용을 추가하고 수정·보완하여 설문지를 완성하였다. 완성된 설문지는 언 어치료전공 대학원생 5 명과 초등학교 교사 5 명을 대상으로 예비실 험을 실시한 후 최종 설문지를 완성하였다. 설문지는 응답자의 일 반적 특성, 초등교사의 다문화에 대한 교육 요구, 이중언어 교육경 험, 이중언어 인식의 4 개 영역 총 28 개의 문항이며, 문항에 대한 응 답은 24 개의 단일선택방식 문항과 4 개의 다중응답 문항으로 구성 하였다. 일반적인 특성은 성별, 연령, 학력, 지역, 경력 등에 대한 것 으로 7문항이며, 다문화 관련 교육 수강 여부, 교육 요구 및 내용, 외 국어 능력 등에 관해 7문항, 초등학교 교사들이 느끼는 다문화아 
Table 1. Participants' characteristics

\begin{tabular}{lc}
\hline Characteristic & $\mathrm{N}(\%)$ \\
\hline Gender & \\
Male & $69(37.1)$ \\
Female & $117(62.9)$ \\
Age & \\
20s & $43(23.1)$ \\
30s & $92(49.5)$ \\
40s & $45(24.2)$ \\
50s & $6(3.2)$ \\
Education & \\
Bachelor's & $141(75.8)$ \\
Master's & $45(24.2)$ \\
Work experience (yr) & \\
1-4 & $51(27.4)$ \\
5-9 & $56(30.1)$ \\
10-14 & $35(18.8)$ \\
15-19 & $32(17.2)$ \\
$\geq 20$ & $12(6.5)$ \\
School type & \\
Elementary school & $78(41.9)$ \\
Special school & $2(1.1)$ \\
Integrated school & $106(57.0)$ \\
Grades of teaching students & \\
1st grader & $120(64.5)$ \\
2nd grader & $66(35.5)$ \\
3rd grader & \\
4th grader & $22(11.8)$ \\
5th grader & $18(9.7)$ \\
Rural areas & $20(10.8)$ \\
\hline & $32(17.2)$ \\
\hline rities & $49(26.3)$ \\
\hline
\end{tabular}

동 지도의 어려움, 이중언어 아동교육 경험 등에 관한 7문항, 이중 언어 습득의 가능성, 이중언어 교육의 필요성, 이중언어 학습방법 등의 이중언어 인식에 관해 7문항으로 구성하였다.

\section{연구 절차}

\section{설문 문항개발}

설문 문항개발을 위해서 선행연구 분석과 초등학교 교사 집단면 담을 실시하였다. 집단면담은 다문화아동 교육경험이 있는 교사 중 집단면담 참여에 동의한 전북지역 초등학교 교사 4 명이 참여하 였으며, 면담진행은 집단면담에 경험이 있는 연구자가 진행하였다. 편안한 면담이 될 수 있도록 조용한 개인 사무실에서 다과와 사용 할 수 있는 메모지, 펜 등을 준비하였으며, 면담을 진행하기 전에 면 담내용에 대하여 미리 알려주었다. 면담시간은 약 1 시간 30 분 정도
진행되었고 더 이상 새로운 내용이 나타나지 않을 때까지 진행하였 으며 참여자 동의를 얻어 면담내용은 녹음하였다. 수집한 자료는 바로 면담에 참여한 공동연구자가 녹음된 파일을 들으며 전사하였 다. 초등학교 교사면담을 통해 수집한 자료 분석 결과와 Hammer 등(2004), Hwang (2018), Kwon (2016)의 연구를 근거로 초등교사 의 다문화에 대한 교육경험 및 요구, 이중언어 교육경험, 이중언어 인식의 4 개 영역 총 28 개의 문항을 개발하였다. 설문 문항의 신뢰 도 검증을 위해서 신뢰도 계수를 산출한 결과 문항 간의 내적일치 도는.87이었다.

예비조사

설문지의 타당도와 신뢰도 확보를 위해서 광주광역시에 거주하 는 언어치료사 5 명, 정읍시 소재 초등학교 교사 5 명을 대상으로 1 차 개발된 설문지의 예비실험을 실시하였다. 예비실험에서는 집단 면담에 참여하였던 교사 3 명을 포함시켜 면담에서 논의된 내용들 이 설문내용으로 제시되었는지 확인하였으며, 예비조사방법은 직 접 배부와 이메일 배부방법을 이용하였다. 예비실험에서 초등학교 유형을 보다 세부적으로 구분할 것, 설문지 내용을 유사한 질문 유 형끼리 묶어서 제시할 것, 응답문항이 다중인지, 단일응답인지 분 명하지 않는 점, 설문 문장내용을 명확하게 제시할 것, 용어를 쉽게 제시할 것 등의 수정제의를 받았다. 제의에 따라 문항 내용이 중복 되거나 불필요한 문항을 삭제하고 문항 영역에 따라 유사한 내용 으로 배열하였으며 질문의 내용이 명확하게 전달될 수 있도록 문항 별 척도, 설문체크 방식 등을 수정하여 최종 설문지를 완성하였다.

\section{본 조사}

설문지 배포는 전라북도 교육청에서 초등학교를 확인하고 사전 에 초등학교에 연락을 취하여 설문조사에 대한 연구의 취지와 목 적을 알리고 협조를 구한 후 200 부의 설문지를 우편으로 배송하였 다. 설문지 배송 후 공동연구자가 초등학교를 방문하여 교사들에 게 연구의 목적과 내용을 재설명하였으며, 설문지 수거는 우편, 직 접방문 등의 방법을 이용하였다. 배부한 설문지 중 195 부를 수거하 였으며 이 중 설문 내용에 제대로 답이 되지 않았거나 응답자에 대 해 누락된 정보가 많은 설문지 9 부를 제외하고 186 부를 최종 분석 하였다.

\section{자료 분석}

통계처리는 SPSS/WIN 통계프로그램 22.0을 사용하였으며 초 등학교 교사들의 다문화 관련 교육 요구와 경험, 다문화아동 교육 경험, 이중언어에 대한 인식 등의 문항에 대하여 빈도분석을 하였 
다. 교사들의 연령, 지역, 담당학년 등의 배경 변인에 따른 인식 차 이를 알아보기 위해서 교차분석을 실시하고 유의도가 $p<.05$ 인 경 우는 통계적으로 의미가 있는 것으로 해석하였다.

\section{연구결과}

\section{초등학교 교사들의 다문화 관련 교육 요구}

조사에 응답한 교사의 $57.5 \%$ 가 다문화 관련 강좌를 수강한 경험 이 있었으며, $81.3 \%$ 가 한 과목을 수강하였다고 답하였다. 수강은 연수과정이 $73.8 \%$, 대학원 교양강좌가 $24.3 \%$ 로 주로 연수과정을 통해서였으며, $86.6 \%$ 의 교사가 다문화와 관련된 교사교육이 필요 하다고 생각하고 있었다. 교육이 필요하다고 응답한 교사를 대상 으로 교육내용에 대해 조사한 결과 학교생활적응 관련이 $27.9 \%$, 언 어발달 관련 교육 $27.4 \%$, 가정문제 관련 $19 \%$, 문화 관련이 $15.6 \%$ 등 의 순으로 요구가 높았다(Table 2).

교사들이 다문화아동 지도 시 교육이나 부모상담을 할 수 있을 정도로 사용할 수 있는 외국어가 있는지 살펴보았다. 응답자 중

Table 2. Multicultural education needs of elementary school teachers

\begin{tabular}{lc}
\hline Classification & $\mathrm{N}(\%)$ \\
\hline Desire to take multicultural education & $107(57.5)$ \\
Yes & $79(42.5)$ \\
No & $186(100)$ \\
Total & \\
Number of courses & \\
1 course & $87(81.3)$ \\
2 courses & $20(18.7)$ \\
Total & $107(100)$ \\
Courses & \\
Training course & \\
University curriculum & $79(73.8)$ \\
Others & $26(24.3)$ \\
Total & $2(1.9)$ \\
Need for multicultural education & $107(100)$ \\
Yes & \\
No & $161(86.6)$ \\
Don't know & $3(1.6)$ \\
Total & $22(11.8)$ \\
Contents for multicultural education & \\
Adaptation to school life & $186(100)$ \\
Language development & \\
Multicultural family problems & $50(27.9)$ \\
Multicultural and bicultural & $49(27.4)$ \\
Psychological problems & $34(19.0)$ \\
Total & $28(15.6)$ \\
\hline & $18(10.1)$ \\
\hline & $179(100)$ \\
\hline
\end{tabular}

Respond only if taken, ${ }^{\mathrm{b}}$ multiple response.
$19.4 \%$ 가 외국어를 할 수 있다고 답하였으며, 사용할 수 있는 외국 어는 영어가 $89.5 \%$, 일본어가 $10.5 \%$ 였다(Table 3 ).

\section{초등학교 교사들의 다문화아동 교육 경험}

교사들이 지도하고 있는 다문화아동의 이중언어사용에 대하여 조사한 결과 이중언어를 “사용하지 않는다" $50.0 \%$, "잘 모르겠다" $25.3 \%$, "사용한다" $20.4 \%$ 이었다. 다문화아동이 사용하는 이중언 어는 한국어-중국어가 $30 \%$, 한국어-베트남어 $27.1 \%$, 한국어-영어 $14.3 \%$ 등이었다(Table 4).

응답한 교사 중 $31.2 \%$ 가 다문화아동에게 이중언어 습득을 권유 한 적이 있다고 하였으며. 권유한 이유로는 정체성 확립으로 오는 내면의 안정감이 $50.0 \%$ 로 가장 많았고, 미래의 교육 및 직업선택의 기회 증가가 $27.6 \%$, 가족 간의 원활한 소통을 통한 학교생활의 적 응 향상이 $15.5 \%, 6.9 \%$ 는 이주자 모국에 대한 이해 증가 때문이었 다. $68.8 \%$ 는 권유하지 않았다고 답하였는데 그 이유는 $38.3 \%$ 가 학

Table 3. Elementary school teachers' ability to use foreign languages

\begin{tabular}{lr}
\hline Classification & $\mathrm{N}(\%)$ \\
\hline Foreign language ability & \\
Yes & $36(19.4)$ \\
No & $150(80.6)$ \\
Total & $186(100)$ \\
Available foreign languages ${ }^{\mathrm{a}}$ & \\
English & $34(89.5)$ \\
Japanese & $4(10.5)$ \\
Total & $38(100)$ \\
\hline
\end{tabular}

${ }^{a}$ Multiple response.

Table 4. Bilingual use of multicultural children in teaching

\begin{tabular}{lc}
\hline Classification & $\mathrm{N}(\%)$ \\
\hline $\begin{array}{l}\text { Whether children should speak two languages } \\
\text { (bilingual language use) }\end{array}$ \\
Should not use two languages & $93(50.0)$ \\
Don't know & $47(25.3)$ \\
Use two languages & $38(20.4)$ \\
Others & $8(4.3)$ \\
Total & $186(100)$ \\
Bilingual language use of the children ${ }^{\mathrm{a}}$ & \\
Korean-Chinese & $21(30.0)$ \\
Korean-Vietnamese & $19(27.1)$ \\
Korean-English & $10(14.3)$ \\
Korean-Thai & $3(4.3)$ \\
Others & $17(24.3)$ \\
Total & $70(100)$ \\
\hline
\end{tabular}

aultiple response. 
업을 따라가기도 벅차서, $28.1 \%$ 는 추후 자연스럽게 이중언어를 학 습할 수 있기 때문이라고 응답하였다. $13.3 \%$ 는 이중언어로 인한 한 국어 습득 지연 염려 때문이라고 했다. 이외 다문화아동의 학습부 진 등의 이유가 있었다(Table 5).

교사의 $28.5 \%$ 가 다문화아동 지도 시 가장 어려운 점으로 학업 부진을 꼽았으며, 심리적인 문제는 $26.3 \%$, 부모와의 소통 $18.3 \%$, 또 래와의 상호작용 부족 $16.1 \%$, 낮은 한국어 능력이 $10.8 \%$ 였다. 다문 화아동이 학교생활에 어려움이 있는 이유로는 또래와의 상호작용

Table 5. Recommendation for the acquisition of bilingual language use and the reason

\begin{tabular}{lc}
\hline Classification & $\mathrm{N}(\%)$ \\
\hline Recommend bilingual language acquisition & $58(31.2)$ \\
Yes & $128(68.8)$ \\
No & $186(100)$ \\
Total & \\
Reasons for recommending bilingual language acquisition & $29(50.0)$ \\
Emotional stability from identity establishment & $16(27.6)$ \\
Increased opportunities in future education and career & $9(15.5)$ \\
Adaptation to school life through communication between families & $4(6.9)$ \\
Increased understanding of mother's country & $58(100)$ \\
Total & \\
Reasons for not recommending bilingual language acquisition & $49(38.3)$ \\
Hard to keep up with their studies & $36(28.1)$ \\
Can be acquired naturally in the future & $17(13.3)$ \\
Worried about delay in Korean language development & $5(3.9)$ \\
Ashamed of being a multicultural child & $12(9.4)$ \\
Others & $119(100)$ \\
\hline Total
\end{tabular}

Table 6. Difficulty of teachers in education for multicultural children

\begin{tabular}{lc}
\hline Classification & $\mathrm{N}(\%)$ \\
\hline Difficulties in teaching multicultural children & \\
Poor academic performance & $53(28.5)$ \\
Psychological problems & $49(26.3)$ \\
Difficulty communicating with parents & $34(18.3)$ \\
Lack of interaction with children's peers & $30(16.1)$ \\
Poor Korean language skills & $20(10.8)$ \\
Total & $186(100)$ \\
Reasons for difficulty in school & \\
Problem of interaction with peers & $58(31.2)$ \\
Psychological instability & $54(29.0)$ \\
Poor academic performance & $29(15.6)$ \\
Poor Korean skills & $22(11.8)$ \\
Negative perception of multicultural families & $21(11.3)$ \\
Others & $2(1.1)$ \\
Total & $186(100)$ \\
\hline
\end{tabular}

문제가 $31.2 \%$, 심리적인 불안정이 $29.0 \%$, 학업부진이 $15.6 \%$, 한국 어를 못하는 것이 $11.8 \%$, 다문화에 대한 부정적인 인식 $11.3 \%$ 등이 었다(Table 6).

\section{초등학교 교사들의 이중언어에 관한 인식}

다문화아동의 이중언어발달에 대하여 질문하였을 때 교사 중 $58.1 \%$ 가 한국어와 어머니 모국어의 두 언어를 습득할 수 있다고 생 각하고 있었으며, $38.7 \%$ 는 두 언어 모두 완벽하지는 않다, $2.2 \%$ 는 가능하지 않다고 답하였다. 다문화아동이 먼저 습득해야 하는 언 어가 무엇인가라는 질문에 $77.4 \%$ 의 교사가 한국어라고 하였으며, 두 언어를 동시에 이중언어로 습득이 $16.7 \%$, 이주자의 모국어가

Table 7. Teachers' perception on bilingual development of multicultural children

\begin{tabular}{lc}
\hline Classification & $\mathrm{N}(\%)$ \\
\hline Perception of bilingual language acquisition & $108(58.1)$ \\
Possible & $72(38.7)$ \\
Neither language is perfect & $4(2.2)$ \\
Impossible & $2(1.1)$ \\
Others & $186(100)$ \\
Total & \\
First language that should be acquired & $144(77.4)$ \\
Korean & $31(16.7)$ \\
Both Korean and mother's native language & $11(5.9)$ \\
Mother's native language & $186(100)$ \\
Total & \\
\hline
\end{tabular}

Table 8. Necessity of bilingual education program for multicultural children

\begin{tabular}{lc}
\hline Classification & $\mathrm{N}(\%)$ \\
\hline Do need bilingual education programs for multicultural children? & \\
Yes & $136(73.2)$ \\
No & $25(13.4)$ \\
Don't know & $25(13.4)$ \\
Total & $186(100)$ \\
Can bilingual ability increase self-esteem of multicultural children? & \\
Yes & $149(80.1)$ \\
No & $18(9.7)$ \\
Don't know & $19(10.2)$ \\
Total & $186(100)$ \\
Who teaches bilingual for the children? & \\
Parents & $129(69.4)$ \\
Language development supporters & $47(25.3)$ \\
Speech-language pathologists & $10(5.4)$ \\
Kindergarten teachers & $0(0)$ \\
Elementary school teachers & $0(0)$ \\
Total & $186(100)$ \\
\hline
\end{tabular}


$5.9 \%$ 였다(Table 7).

다문화아동을 위한 이중언어 교육프로그램의 필요성에 대하여 응답한 교사의 $73.2 \%$ 는 필요하다고 하였으며, 필요하지 않다, 모르 겠다가 각 $13.4 \%$ 였다. 누가 다문화아동에게 이중언어를 가르쳐야 하는가에 대한 질문에 부모가 가르쳐야 한다고 응답한 비율이 $69.4 \%$, 언어발달지도사 $25.3 \%$, 언어치료사 $5.4 \%$ 였다. 또한 이중언 어와 다문화아동의 자존감에 대한 인식에서 응답한 교사의 $80 \%$ 가 이중언어를 습득함으로써 자존감을 높일 수 있다고 생각하고 있었다(Table 8).

초등학교 교사들이 생각하는 이중언어 학습시기는 유치원 시기 가 $46.2 \%$, 출생 이후 바로 $34.4 \%$, 초등학교 시기가 $14.0 \%$, 중학교 시기가 $2.7 \%$ 등의 순이었다. 가장 효과적인 이중언어 학습방법은 다문화 부모가 각자의 언어를 자녀에게 사용하는 것이 $61.3 \%$, 관련 언어학습기관 이용이 $23.1 \%$, 모국방문을 통해 노출시킨다는 응답 이 $12.4 \%$, 책, 미디어 등을 이용이 $3.2 \%$ 등이었다(Table 9).

초등학교 교사들의 경력, 학력, 연령, 지역, 근무 유형의 배경 변인
에 따른 이중언어 교육의 필요성과 이중언어 습득에 대한 인식 차 이를 살펴보았다. 이중언어 교육의 필요성에 대한 인식에서는 연령

Table 9. When and how to learn bilingual for multicultural children

\begin{tabular}{lr}
\hline Classification & $\mathrm{N}(\%)$ \\
\hline The right time to learn bilingual & \\
At the age of kindergarten & $86(46.2)$ \\
Immediately after birth & $64(34.4)$ \\
In elementary school years & $26(14.0)$ \\
In middle school years & $5(2.7)$ \\
In high school years & $2(1.1)$ \\
Others & $3(1.6)$ \\
Total & $186(100)$ \\
Effective bilingual learning methods & \\
By the way parents using their own language to their children & $114(61.3)$ \\
Using relevant language learning institutions & $43(23.1)$ \\
Visiting mother's country and exposing native language & $23(12.4)$ \\
Using books, media, etc. & $6(3.2)$ \\
Total & $186(100)$ \\
\hline
\end{tabular}

Table 10. Difference in necessity of bilingual education by background variables

\begin{tabular}{|c|c|c|c|c|c|}
\hline \multirow{2}{*}{ Variable } & \multicolumn{3}{|c|}{ Necessity of bilingual education } & \multirow{2}{*}{ Total } & \multirow{2}{*}{$\chi^{2}$ (p-value) } \\
\hline & Yes & No & Don't know & & \\
\hline Working areas & & & & & $.276(.871)$ \\
\hline Cities & $89(74.2)$ & $15(12.5)$ & $16(13.3)$ & $120(100)$ & \\
\hline Rural area & $47(71.2)$ & $10(15.2)$ & $9(13.6)$ & $66(100)$ & \\
\hline Age & & & & & $18.944^{* *}(.004)$ \\
\hline $20 \mathrm{~s}$ & $32(74.4)$ & $0(0.0)$ & $11(25.6)$ & $43(100)$ & \\
\hline $30 \mathrm{~s}$ & 71 (77.2) & $12(13.0)$ & $9(9.8)$ & $92(100)$ & \\
\hline $40 \mathrm{~s}$ & $29(64.4)$ & $11(24.4)$ & $5(11.1)$ & $45(100)$ & \\
\hline $50 \mathrm{~s}$ & $4(66.7)$ & 2 (33.3) & $0(0.0)$ & $6(100)$ & \\
\hline Work experience (yr) & & & & & $25.222^{* * *}(.001)$ \\
\hline $1-4$ & $39(76.5)$ & $2(3.9)$ & $10(19.6)$ & $51(100)$ & \\
\hline $5-9$ & 44 (78.6) & $2(3.6)$ & $10(17.9)$ & $56(100)$ & \\
\hline $10-14$ & $23(65.7)$ & $10(28.6)$ & $2(5.7)$ & $35(100)$ & \\
\hline 15-19 & $22(68.8)$ & $7(21.9)$ & $3(9.4)$ & $32(100)$ & \\
\hline$\geq 20$ & $8(66.7)$ & $4(33.3)$ & $0(0.0)$ & $12(100)$ & \\
\hline School type & & & & & $2.141(.710)$ \\
\hline Elementary school & $56(71.8)$ & $9(11.5)$ & $13(16.7)$ & $78(100)$ & \\
\hline Special children & $2(100.0)$ & $0(0.0)$ & $0(0.0)$ & $2(100)$ & \\
\hline Integrated school & $78(73.6)$ & $16(15.1)$ & $12(11.3)$ & $106(100)$ & \\
\hline Grades of teaching students & & & & & $17.062(.073)$ \\
\hline 1st grader & $14(63.6)$ & $6(27.3)$ & $2(9.1)$ & $22(100)$ & \\
\hline 2nd grader & $11(61.1)$ & $5(27.8)$ & $2(11.1)$ & $18(100)$ & \\
\hline 3rd grader & $15(75.0)$ & $3(15.0)$ & $2(10.0)$ & $20(100)$ & \\
\hline 4th grader & 22 (68.8) & $6(18.8)$ & $4(12.5)$ & $32(100)$ & \\
\hline 5th grader & $36(73.5)$ & $2(4.1)$ & $11(22.4)$ & $49(100)$ & \\
\hline 6th grader & 38 (84.4) & $3(6.7)$ & 4 (8.9) & $45(100)$ & \\
\hline
\end{tabular}

Values are presented as number (\%). 
$\left(\chi^{2}=18.944, p<.01\right)$, 경력 $\left(\chi^{2}=25.222, p<.001\right)$ 에서 차이가 있었다. 연령에서는 20 대가 $74.4 \%, 30$ 대는 $77.2 \%, 40$ 대는 $64.4 \%, 50$ 대는 $66.7 \%$ 로 대체로 연령이 낮을수록 이중언어 교육이 필요하다는 응 답이 많았다. 경력에서는 1-5년 미만은 필요하다는 응답이 $76.5 \%$, 5-10년 미만 78.6\%, 10-15년 미만 65.7\%, 15-20년 미만 68.8\%, 20년 이상은 $66.7 \%$ 로 대체로 경력이 짧을수록 이중언어 교육이 필요하 다는 응답이 높게 나타났으며 이외 학력, 학교 유형 등에서는 통계 적인 차이가 없었다(Table 10).

이중언어 습득에 대한 인식은 근무지역 $\left(\chi^{2}=15.884, p<.001\right)$ 에 서 통계적으로 유의미한 차이가 있었다. 군지역에 근무하는 교사들 의 이중언어 습득이 가능하다는 응답비율이 $72.7 \%$, 시지역은 $50 \%$ 였다. 이외 담당학년, 경력, 연령, 학교 유형 등에서는 통계적으로 유 의미한차이가 없었다.

\section{논의 및 결론}

최근 학령기 다문화아동의 수가 증가하고 교육환경에서 한국어 를 제 2 언어로 습득하는 중도입국 아동들이 교육을 받는 사례가 늘 어남에 따라 이들의 자아감과 정체성 등에 긍정적인 영향을 줄 수 있는 이중언어 습득에 대한 관심과 논의가 시작되고 있다. 이에 본 연구에서는 교육환경에서 학생들에게 직접적으로 서비스를 제공 하고 있고 이중언어 습득에 영향을 줄 수 있는 초등학교 교사를 대 상으로 다문화관련 교육 요구, 다문화아동 교육 경험, 이중언어에 대한 인식 등을 살펴보고 교육현장과 연계와 협력을 위한 언어치료 분야의 역할에 대하여 탐색해 보고자 하였다.

초등학교 교사의 다문화 교육 수강실태와 교육 요구를 분석한 결과 응답한 교사 중 $57.5 \%$ 가 다문화 관련 교육을 받은 것으로 나 타났다. 응답자의 대다수가 1 과목을 수강하였고 주로 연수과정에 서 교육을 받은 것으로 나타나 초등학교 교사들의 다문화 관련 교 육은 학부나 대학원의 교육과정이 아닌 주로 졸업 이후에 이루어 진 것으로 나타났다. 다문화 관련 교육 요구에서는 다문화아동의 학교생활문제, 언어발달에 관한 요구가 높았다. 초등학교의 다문화 교육과정과 국가정책이 학교생활적응과 한국어 습득 중심으로 이 루어져 있음에도(Park, Jo, \& Kim, 2016) 불구하고 교육현장에서는 이러한 문제로 어려움을 겪고 있다는 것을 알 수 있었다. 학령기 다 문화아동들의 언어습득 문제는 크게 세가지로 살펴볼 수 있는데 첫째는 초등학교에 입학해서도 여전히 기본적인 언어능력을 습득 하지 못한 아동들이 있으며, 둘째는 학령전기에 기분적인 언어능력 을 습득하였으나 교과와 관련된 학업어휘, 담화, 이야기, 읽기와 쓰 기 등에는 문제가 있는 경우이며, 셋째는 중도입국이나 노동이주
등과 같은 자녀들이 한국어를 습득하지 못한 채 한국어로 학교교 육을 받는 경우이다. 본 연구에서 교사들의 언어발달에 대한 요구 는 이러한 상황에서 발생하는 학생지도의 어려움이 반영된 것으로 추측된다.

교사들이 교육한 다문화아동 중 이중언어를 사용하는 비율이 $20.4 \%$, 사용하지 않은 비율은 $50 \%$ 였으며, 약 $30 \%$ 는 모르겠다고 응 답하였다. 이를 볼 때 약 $20 \%$ 정도의 아동들이 이중언어를 사용하 는 것으로 볼 수 있으며 이 비율은 다문화어머니를 대상으로 한 약 40\% (Hwang \& Kang, 2016; KIHF, 2018) 보다는 낮은 수준이나상 당한 수의 학령기 다문화아동이 이중언어를 사용하는 것으로 볼 수 있다. 다문화아동들이 사용하는 이중언어는 한국어-중국어가 $30 \%$, 한국어-베트남어 $27.1 \%$, 한국어-영어 $14.3 \%$ 등이었는데 이는 우리나라 다문화어머니의 출신국 비율이 반영된 것으로 보인다 (KIHF, 2018). 또한 교사 중 19.4\%는 다문화아동 지도 시에 부모상 담을 할 수 있을 정도로 사용할 수 있는 외국어가 있다고 응답하였 는데, 사용 가능한 외국어는 영어가 $89.5 \%$, 일본어가 $10.5 \%$ 였다. 다 문화가정의 언어환경이 중국어, 베트남어 등이 대다수이기에 교사 의 외국어 능력이 아동이나 부모와의 소통에서 역할을 하기에는 한계가 있을 것으로 보인다.

교사 중 $31.2 \%$ 는 다문화아동에게 이중언어 습득을 권유한 적이 있다고 하였으며 그 이유는 정체성 확립에서 오는 내면의 안정감 때문이었다. 또한 $80.1 \%$ 가 이중언어 습득으로 아동들의 자존감이 향상될 수 있다고 생각하고 있었다. 실제 우리나라 다문화아동들 이 이중언어를 사용함으로써 자신감과 자아존중감이 높아진 사례 를 보고하고 있으며(Shin \& Song, 2018). 긍정적인 정체성 형성을 위해 모국어 또는 소수언어 습득과 유지를 강조하고 있다(Paradis et al., 2011; Wong Fillmore, 1991). 이중언어 습득을 권유한 이유 중 미래의 교육 및 직업선택의 기회 증가, 가족 간의 원활한 소통을 통 한 학교생활의 적응 향상, 이주자 모국에 대한 이해 증가 등에 대한 응답빈도도 높은 것을 볼 때 교사들이 이중언어 사용의 이점을 잘 알고 있다고 할수 있을 것 같다.

한편 교사들이 이중언어 습득을 권유하지 않은 가장 큰 이유는 학업문제였다. 이는 학령기 다문화아동들이 읽기 및 쓰기에서 어 려움이 있고 이것이 학업성취에서 낮은 수행력으로 연결되기에 (Jung, Hwang, Pae, \& Kim, 2015; KYCI, 2011) 학업문제 해결을 더 긴급하기 생각하고 있는 것으로 보인다. 또한 교사들은 이중언어는 추후에 자연스럽게 습득할 수 있다고 생각하고 있었으며, 이중언어 로 인해 한국어 습득 지연을 염려하고 있었다. 우리나라 다문화가 정의 사회경제적 수준, 지역사회 언어환경, 교육환경 등을 고려하 였을 때 학령기 다문화아동들이 한국어와 어머니 모국어를 자연 
스럽게 습득하기에는 한계가 있고(Hwang, 2019), 많은 연구에서 이중언어 습득이 언어발달 지연을 유발하지 않는다는 결과를 밝히 고 있다(Paradis et al., 2011). 교사들의 이러한 인식은 미국이나 유 럽의 단일언어를 사용하는 교사들에게도 유사하게 나타나는 현상 이며(Garrity et al., 2018), 그 이유 중 하나가 이중언어발달에 대한 이해부족으로 보고 있다(Lee et al., 2015).

교사들이 경험하고 있는 다문화아동 지도의 어려움은 학업부 진, 심리적인 문제, 부모와의 소통, 또래와의 상호작용 순으로 꼽고 있었다. 다문화아동이 학교생활에서 어려움을 겪고 있는 이유도 유사하게 또래와의 상호작용, 심리적인 불안정, 학업부진, 한국어 능력에 관한 것이었다. 이를 볼 때 다문화아동들이 여러 선행연구 에서 보고하고 있는 학업부진, 심리적인 문제와 함께 언어문제를 가지고 있으며 이로 인해 지도하는 교사와 배우는 학생 모두 어려 움을 겪고 있는 것을 알 수 있었다. 이것은 다문화가족 자녀 언어발 달지원사업에 의뢰되는 초등학생수가 해마다 증가하는 현상으로 도 확인할 수 있다(KIHF, 2018). 최근 5년간 언어발달지원사업에서 언어촉진서비스를 받은 학령기 아동은 2013년 845명에서 2014년 1,038 명, 2017년 1,967명으로 증가하였다. 많은 다문화아동들이 학 교생활이나 학업에 필요한 한국어 능력 부족이 학교생활과 학업문 제로 이어지고 이중언어 습득이나 또래와의 상호작용, 자존감, 심 리적인 측면까지 영향을 끼치고 있다고 볼수 있을 것 같다.

다문화아동의 이중언어 습득과 사용에 관한 교사들의 인식을 살펴본 결과 $58.1 \%$ 가 이중언어를 습득할 수 있다고 생각하고 있었 으며, $38.7 \%$ 는 두 언어 모두 완벽하지는 않다, $2.2 \%$ 는 가능하지 않 다고 답하여 대체로 긍정적이었다. 그러나 이중언어에 대한 긍정적 인 인식에도 불구하고 교사 중 $77.4 \%$ 는 한국어를 먼저 배워야 한다 고 답하였는데 그 이유 중 $91 \%$ 가 국어이고 한국사회에 적응, 의사 소통하기 위해서 필요하기 때문이라고 하였다. 이러한 현상은 미국 이나 유럽의 교사 인식에서도 발견할 수 있다. 교사들이 이중언어 와 이중언어교육에 대해 호의적이고 이중언어 개발에 대한 지식이 있음에도 불구하고 실제 이중언어에 대해서는 부정적인 태도를 보 이는 경향이 있다. 이는 교사들의 이중언어발달에 대한 정보가 부 족하거나, 교육환경에서 사용하는 언어가 그 나라의 주언어인 단일 언어이기 때문이라고 분석하고 있다(Garrity et al., 2018). 우리나라 도 학교에서 교육언어가 한국어이기에 교사들이 다문화아동들의 이중언어 습득의 혜택을 알고 있으나 우선적으로 학업성취와 학교 생활을 위해서 한국어 습득을 중요하게 생각하는 것으로 보인다.

교사들의 $73.1 \%$ 가 이중언어교육의 필요성에 대하여 긍정적으로 답하였으나 이중언어교육은 부모, 언어발달지도사, 언어치료사가 해야 한다고 응답하였다. 이는 우리나라의 초등학교 다문화교육이
한국어교육, 학교생활적응, 문화적응에 초점을 두고 있고(Park et al., 2016) 교사들은 아동들의 학업부진 문제를 해결하기에도 벅차 기 때문에 이중언어교육은 교사 자신들 보다 부모나 언어치료전공 자가 해야 한다고 생각하는 것으로 보인다. 이는 궁극적으로 교사 들이 다양한 요구를 가진 다문화아동들에게 교육서비스를 제공하 기 위해서는 언어치료전공과 협력이 필요하다는 것을 인식하고 있 다는 것으로 추측할 수 있을 것 같다. 언어치료사와 교사 간 협력의 장점은 접근하는 방식은 다르지만 서로 보완적인 측면이 있기 때문 이다. 즉, 전문가 간의 지식과 기술을 서로 공유할 수 있고(Kersner, 1996; Tollerfield, 2003; Wright \& Kersner, 2004), 아동들이 배우고 있는 교과 과정과 필요한 치료 요구를 모두 충족시키는 접근방법 을 적용할 수 있는 장점이 있다(Tollerfield, 2003; Wright \& Kersner, 2004). 특히 교육환경에서 이중언어 교육에 대한 인프라가 구 축되어 있지 않을 경우 언어치료사가 교사와 협력하여 다문화아동 에게 제 2 언어 습득을 위한 교육서비스를 제공하는데 동의하고 있 다(Sanger, Hux, \& Griess, 1995).

우리나라의 이중언어교육은 여성가족부 산하 창출 직업인 이중 언어코치가 다문화가족 부모를 중심으로 이중언어 코칭을 하고 있 으나 취학전 아동 부모로 대상을 제한하고 있다(MOGEF, 2019). 학 교환경에 이중언어에 대한 인프라가 거의 구축되어있지 않기 때문 에 학령기 다문화아동의 이중언어발달과 관련된 정보제공은 거의 언어발달지도사의 역할이라고 볼 수 있다. 언어발달지도사들은 결 혼이민자 자녀들의 모국어로서 한국어 습득, 중도입국 아동들의 제 2 언어로서 한국어 습득 등을 위한 교육서비스를 제공하는 직업 군이다(KIHF, 2018). 특히 학령기 중도입국 아동들의 경우 언어차 이로 인한 소통의 문제를 해결하기 위해 통번역사를 활용하여 교 육서비스를 제공하고 있으며, 모국어 또는 제 2 언어로서 한국어 습 득과 촉진, 그리고 이중언어 습득과 유지 등에 관해 부모교육과 상 담을 제공하고 있기에(Hwang, 2019) 다문화아동들의 이중언어와 관련하여 실제적인 역할을 하고 있다고 볼 수 있다. 우리나라도 미 국이나 캐나다 등의 모델처럼 숙원으로 하고 있는 학교 언어치료사 진입을 위해서는 학교환경에서 다문화아동과 관련된 언어치료전 공자에 대한 여러 역할 논의가 필요하다고 본다.

초등학교 교사들이 생각하는 이중언어 학습 시기는 유치원 시기 가 $46.2 \%$, 출생 후 바로 $34.4 \%$, 초등학교 시기가 $14.0 \%$, 중학교 시 기가 $2.7 \%$ 등의 순이었다. 대개 이중언어발달은 습득 연령이 어릴 수록 두 언어를 동등한 수준으로 습득할 가능성이 높고(Paradis et al., 2011), 인지적 유연성이나 인지발달에 긍정적이라는(Peal \& Lambert, 1962) 연구결과를 보고함에도 불구하고 교사들은 동시적 이 중언어발달 형태보다 순차적 또는 제 2 언어 습득을 더 선호하는 것 
으로 나타났다. 이는 그간 많은 연구에서 보고하고 있는 다문화아 동들의 학업성취, 학교생활적응, 한국생활적응 등을 위해서는 우 리나라 교육언어인 한국어를 먼저 습득해야 한다는 교사들의 경험 이 반영된 것으로 보이며, 한편으로는 이중언어발달에 대한 정보와 이해 부족인 것으로 추측된다. 한편, 이중언어 학습방법에 있어서 는 부모, 관련 언어학습기관, 모국방문 등의 방법을 선호하였는데 이는 다문화어머니들이 선호하는 이중언어 교육방법과 유사하였 다(Hwang, 2018). 교사들의 인구사회학적인 변인에 따른 인식차이 에서는 이중언어 교육 필요성에서 연령 및 경력, 이중언어 습득에 대한 인식에서는 근무지역에서만 차이가 있었다. 대체로 교사들의 연령이 낮고 경력이 짧은 젊은 교사들이 이중언어에 대하여 긍정적 으로 인식하고 있었다.

본 연구결과를 종합하여 초등학교 교육현장과 언어치료 분야의 연계 및 협력을 위한 제안을 하면 다음과 같다. 첫째, 초등학교 교 사들의 다문화와 관련된 교육 요구에서 언어발달에 대한 요구가 높았다. 언어발달은 한국어 습득과 이중언어 습득 둘 모두의 요구 라고 볼 수 있으며 언어발달에 대한 이해교육과 정보를 제공하는 것이 언어치료 분야의 역할 중 하나이다. 미국을 중심으로 국외에 서는 교육환경과의 협력을 위해 대상자들에게 직접 치료서비스를 제공하는 직무에 관련 전문가들의 협력, 자문, 정보제공을 위한 교 육연수자로서의 역할을 추가하고 있다(Ehren, 2000). 따라서 초등 학교 교사를 포함하여 여러 교육환경에 있는 전문가들에게 다문 화아동들의 언어발달에 대한 교육을 제공하는 연수자로서의 역할 에 대하여 논의가 필요하여 보인다. 이를 위해서는 우선적으로 언 어치료사를 대상으로 다문화아동의 언어발달, 이중언어발달, 언어 결함 특성 등에 대한 세미나, 연수 등을 활성화해야 할 것이며, 이러 한 교육 기회를 통하여 다문화아동들의 전반적인 언어발달에 대한 언어치료사들의 지식적 역량을 강화시켜야 할 것이다.

둘째, 학령기 다문화아동들이 여전히 언어발달 문제를 겪고 있 었으며 이는 교육서비스 제공자인 교사와 대상인 아동 둘 모두에 게 처한 어려움이었다. 학령기 다문화아동에게 일상생활과 학업에 필요한 언어능력과 읽기쓰기 기술을 촉진시키는 역할을 언어치료 전공자인 언어발달지도사가 담당하고 있기에 교육학과 언어병리 학, 그리고 교사와 언어치료사가 다학문적으로 접근하고 상호교류 를 해야 할 것이다. 여러 분야에서 전문적이고 효율적인 서비스 제 공을 위해서 전문가 간, 또는 다학문 간 협력의 중요성을 인정하고 있다. 그러나 시간부족, 협력기술의 부족, 과중한 업무 등의 여러 가 지 이유로 쉽지 않은 것이 현실이기에 점진적인 변화와 장기적인 시 간이 필요할 것이다. 따라서 교사와 언어치료사가 다문화아동과 관련된 정보를 서로 교환하는 것에서 시작하여 협력을 위한 목표
와 각 분야의 역할에 대하여 함께 교육이나 연구를 계획하는 것이 필요하여 보인다.

셋째, 교사들의 이중언어 습득과 필요성에 대한 인식이 긍정적이 고 학생들에게 이중언어 습득을 권고하고 있지만 실제로 이중언어 교육은 교사가 아닌 부모, 언어치료사, 언어발달지도사의 역할이라 고 생각하고 있었다. 교육현장에 이중언어교육에 대한 인프라가 거 의 없는 우리나라에서 언어발달지도사가 학령기 다문화아동의 언 어발달, 이중언어발달에 대한 부모교육과 상담 등을 담당하고 있 는 것이 현실이며, 외국의 경우에도 교육환경에 인프라가 없는 경 우 언어치료사가 그 역할을 하고 있다. 따라서 교육현장과 언어치 료 분야에서 이에 대한 구체적인 요구와 실행 방안, 교사와 언어치 료사들의 태도, 경험 등에 대하여 기초연구를 실시하고 교육환경 과 연계하고 협력할 수 있는 방안을 모색해야 할 것이다.

\section{REFERENCES}

Adler, S. (1990). Multicultural clients: implications for the SLP. Language, Speech, and Hearing Services in Schools, 21(3), 135-139.

Ahn, J. B. (2013). The study on elementary school teachers' recognition toward stuttering students in inclusive environment. Journal of Special Children Education, 15(1), 315-333.

Antoniazzi, D., Snow, P., \& Dickson-Swift, V. (2010). Teacher identification of children at risk for language impairment in the first year of school. International Journal of Speech-Language Pathology, 12(3), 244-252.

Babad, E. Y., Inbar, J., \& Rosenthal, R. (1982). Pygmalion, Galatea, and the Golem: investigations of biased and unbiased teachers. Journal of Educational Psychology, 74(4), 459-474.

Bae, J. H., \& Bong, J. Y. (2012). Mothers' experiences of child rearing in multicultural families. Journal of Early Childhood Education, 32(3), 383-405.

Chu, G., \& Choi, M. (2017). Consideration of idiosyncratic features in bilingualism and the education methods focusing on Korean Huaqiao. Journal of Learner-Centered Curriculum and Instruction, 17(6), 83-105.

Crowl, T. K., \& MacGinitie, W. H. (1974). The influence of students' speech characteristics on teachers' evaluations of oral answers. Journal of Educational Psychology, 66(3), 304-308.

Dockrell, J. E., \& Lindsay, G. (2001). Children with specific speech and language difficulties: the teachers' perspective. Oxford Review of Education, 27(3), 369-394.

Ehren, B. J. (2000). Maintaining a therapeutic focus and sharing responsibility for student success: keys to in-classroom speech-language services. Lan- 
guage, Speech, and Hearing Services in Schools, 31(3), 219-229.

Friend, M., \& Cook, L. (2000). Interactions: collaboration skills for school professionals (3rd ed.). New York, NY: Longman.

Garrity, S., Aquino-Sterling, C. R., Van Liew, C., \& Day, A. (2018). Beliefs about bilingualism, bilingual education, and dual language development of early childhood preservice teachers raised in a Prop 227 environment. International Journal of Bilingual Education and Bilingualism, 21(2), 179196.

Godley, A. J., Sweetland, J., Wheeler, R. S., Minnici, A., \& Carpenter, B. D. (2006). Preparing teachers for dialectally diverse classrooms. Educational Researcher, 35(8), 30-37.

Hammer, C. S., Detwiler, J. S., Detwiler, J., Blood, G. W., \& Qualls, C. D. (2004). Speech-language pathologists' training and confidence in serving Spanish-English Bilingual children. Journal of Communication Disorders, 37(2), 91-108.

Harn, W. E., Bradshaw, M. L., \& Ogletree, B. T. (1999). The speech-language pathologist in the schools: changing roles. Intervention in School and Clinic, 34(3), 163-169.

Hwang, S. S. (2018). A qualitative study of children' bilingual use in multicultural families in Korea. Journal of Speech-Language \& Hearing Disorder, 27(1), 99-113.

Hwang, S. S. (2019). Dual language use of children with culturally and linguistically diverse backgrounds and interpreter cooperation during service delivery in Korea. Journal of Speech-Language \& Hearing Disorders, 28(1), $38-46$.

Hwang, S. S., \& Kang, B. J. (2016). A study of the bilingual language use of children from culturally and linguistically diverse backgrounds. Journal of Speech-Language \& Hearing Disorders, 25(1), 123-134.

Jang, U, Y., \& Jeong, K. S. (2012). The relationship between elementary school teachers' perception and the executive ability of multicultural education. Journal of Elementary Education Studies, 19(1), 91-110.

Jeong, E., \& Yu, G. (2009). A survey of perceptions about communication disorders and demands for supports in special educators. Journal of Special Children Education, 11(2), 53-73.

Jung, K. H., Hwang, S. S., Pae, S. Y., \& Kim, M. B. (2015). Qualitative followup study on the effects of language facilitation for children with multicultural backgrounds. Journal of Speech-Language and Hearing Disorders, 24(4), 361-378.

Jung, Y. H. (2012). Determinants of multicultural children's academic achievement. Korean Journal of International Migration, 3(1), 25-36.
Kang, H. K., \& Park, E. (2006). Influence of the classroom-based language intervention on the communication of young children with disabilities: with collaboration between special education teacher and therapeutic education teacher. Korean Journal of Special Education, 41(2), 173-197.

Kersner, M. (1996). Working together for children with severe learning disabilities. Child Language Teaching and Therapy, 12(1), 17-28.

Kim, S. J., Choi, S. S., \& Kim, J. Y. (2006). Perception of special educators on speech therapy service model in inclusive school contexts. Korean Journal of Communication \& Disorders, 11(1), 121-139.

Korean Institute Healthy Family. (2018). Data on multicultural family support service for children's language development in 2018. Seoul: Author.

Korean Youth Counselling \& Welfare Institute. (2011). Current status and improvement tasks of multicultural youth. Seoul: Author.

Kwon, Y. (2016). A study on the perceptions of teachers towards multicultural children' bilingual education. The Korea Association of Child Care and Education, 101, 117-140.

Lee, K. (2013). Perception toward stuttering by teachers in Daegu area. Communication Sciences \& Disorders, 18(4), 447-458.

Lee, M., Shetgiri, R., Barina, A., Tillitski, J., \& Flores, G. (2015). Raising bilingual children: a qualitative study of parental attitudes, beliefs, and intended behaviors. Hispanic Journal of Behavioral Sciences, 37(4), 503-521.

Lee, S. S., \& Kwon, K. S. (2018). An exploratory study of bilingual children from multicultural families. Korean Journal of Children's Media, 17(1), 299320.

Lindsay, G., \& Dockrell, J. E. (2004). Whose job is it? Parents' concerns about the needs of their children with language problems. The Journal of Special Education, 37(4), 225-235.

Ministry of Education. (2018). 2018 multicultural education support plan. Seoul: Ministry of Education.

Ministry of Gender Equality and Family. (2019). 2019 Multicultural family support project. Seoul: Author.

Mroz, M. (2006). Providing training in speech and language for education professionals: challenges, support and the view from the ground. Child Language Teaching and Therapy, 22(2), 155-176.

Paradis, J., Genesee, F., \& Crago, M. B. (2011). Dual language development and disorders: a handbook on bilingualism and second language learning. Baltimore, MD: Paul H. Brookes Publishing.

Park, C., Jo, J., \& Kim, Y. (2016). For the better future: a qualitative case study on the dilemma of the multi-cultural curriculum in Korean elementary school. Multicultural Education Studies, 9(1), 185-213. 
Park, S. H., \& Chang, H. S. (2003). Collaborative teaming between teachers and speech pathologists for classroom-based language interventions in school settings. Korean Journal of Communication \& Disorders, 8(1), 117143.

Peal, E., \& Lambert, W. E. (1962). The relation of bilingualism to intelligence. Psychological Monographs: General and Applied, 76(27), 1-23.

Rosenthal, R., \& Jacobson, L. (1968). Pygmalion in the classroom: teacher expectation and pupils' intellectual development. New York, NY: Holt, Rinehart and Winston.

Sanger, D. D., Hux, K., \& Griess, K. (1995). Educators' opinions about speechlanguage pathology services in schools. Language, Speech, and Hearing Services in Schools, 26(1), 75-86.

Shaddock, T., King, B. S., \& Giorcelli, L. (2007). Project to improve the learning outcomes of students with disabilities in the early, middle and post compulsory years of schooling. Canberra, Australia: Dept. of Education, Science and Training.

Shin, K., \& Song, W. I. (2018). A case study on the dual-language use of multicultural youth. The Multicultural Child and Youth Studies, 3(2), 99-117.

Shin, Y. J., \& Youn, C. Y. (2010). Bicultural adjustment, peer relationship and bicultural acceptance attitude of children in multi-cultural family. The Journal of Play Therapy, 14(2), 1-14.

Statistics Korea. (2019). Youth statistics. Daejeon: Author.

Tak, H. J., Kim, J. B., \& Moon, K. S. (2014). The relationship among Korean language abilities, self-efficacy, teacher's perceptions of multi-cultural edu- cation, student-teacher attachment relationships and school adjustment for multi-cultural students. Korean Journal of Educational Psychology, 28(1), 23-39.

Terrell, B. Y., \& Hale, J. E. (1992). Serving a multicultural population: different learning styles. American Journal of Speech-Language Pathology, 1(2), 5-8.

Tollerfield, I. (2003). The process of collaboration within a special school setting: an exploration of the ways in which skills and knowledge are shared and barriers are overcome when a teacher and speech and language therapist collaborate. Child Language Teaching and Therapy, 19(1), 67-84.

Toppelberg, C. O., \& Collins, B. A. (2010). Language, culture, and adaptation in immigrant children. Child and Adolescent Psychiatric Clinics, 19(4), 697717.

Wong Fillmore, L. (1991). Second language learning in children: a model of language learning in social context. In E. Bialystok (Ed.), Language processing in bilingual children (pp. 49-69). New York, NY: Cambridge University Press.

Wright, J. A., \& Kersner, M. (1999). Teachers and speech and language therapists working with children with physical disabilities: implications for inclusive education. British Journal of Special Education, 26(4), 201-205.

Wright, J. A., \& Kersner, M. (2004). Short-term projects: the standards fund and collaboration between speech and language therapists and teachers. Support for Learning, 19(1), 19-23. 


\section{국문초록}

\section{교육환경과 언어치료 분야의 협력을 위한 학령기 다문화아동 이중언어 사용에 대한 초등학교 교사의 인식 조사 정민지 · 황상심}

남부대학교 언어치료학과

배경 및 목적: 본 연구는 다문화아동의 이중언어 사용과 관련하여 초등학교 교사의 경험, 인식 등을 조사하고 그에 따른 언어치료 분 야와의 협력과 연계 방안을 살펴보고자 하였다. 방법: 선행연구 분석과 교사 집단면담을 통해 기초설문지를 구성하고 예비실험을 거쳐 최종설문지를 완성하였다. 전라북도 지역에 근무하는 교사들에게 설문지를 배포하여 189 개의 설문지를 수거하고 빈도분석과 교차분 석을 통해 결과를 산출하였다. 결과: 교사의 $57.5 \%$ 가 다문화 관련 수강을 하였고 아동의 학교생활문제, 언어발달에 관한 교사 교육 요 구가 높았다. 다문화아동 중 $20.4 \%$ 가 이중언어를 사용하고 있었고, 교사 중 $31.2 \%$ 는 이중언어습득을 권유하였다. 교사들은 이중언어 습득에 대하여 대체로 긍정적이었으나 대다수의 교사가 한국어를 먼저 배워야 한다고 생각하고 있었다. 이중언어교육의 필요성에 대해 서도 긍정적이었으며, 이중언어교육은 부모, 언어발달지도사, 언어치료사 등이 제공해야 한다고 답하였다. 이중언어학습 시기는 유치 원 때, 태어나자마자, 초등학교 시기 등의 순서로 응답하였다. 배경 변인에 따른 인식의 차이를 살펴본 결과 이중언어습득에서는 근무지 역, 이중언어교육의 필요성에서는 연령, 경력에서 통계적인 차이가 있었다. 논의 및 결론: 교사들은 다문화아동의 이중언어 사용에 대 하여 긍정적이었으나 학업, 학교생활, 한국어습득 등의 문제를 시급하게 생각하고 있었다. 다문화아동들의 이중언어를 포함한 언어습 득과 관련하여 교육현장과 언어치료 분야의 협력과 연계가 필요하여 보인다.

핵심어: 이중언어, 학령기 다문화아동, 초등학교 교사, 교육환경, 언어치료사, 협력

본 논문은 정민지(2018)의 석사학위논문을 수정.보완하여 작성한 것임.

본 논문은 2019년도 남부대학교 학술연구비의 지원을 받아 연구되었음.

\section{참고문헌}

강혜경, 박은혜(2003). 특수교사와 치료교사간 협력적 접근을 통한 교실중심 언어중재가 장애유아의 의사소통에 미치는 영향. 특수교육연구, $41(2)$, 173-197.

교육부(2018). 2018년 다문화교육 지원계획. 서울: 교육부.

권이정(2016). 다문화 가정 유아의 이중언어 교육에 대한 유아교사 인식조사. 한국영유아보육학, 101, 117-140.

김수진, 최승숙, 김정연(2006). 특수학급 교사들의 학교언어치료 서비스 모형에 관한 인식조사. 언어청각장애연구, 11(1), 121-139.

박승희, 장혜성(2003). 교실중심 언어중재를 위한 교사와 언어치료사의 협력적 역할 수행. 언어청각장애연구, 8(1), 117-143.

박창민, 조재성, 김영천(2016). 더 나은 미래를 위하여: 우리나라 초등학교 현장에서의 다문화교육과정의 딜레마들에 관한 질적 사례연구. 다문화교

육연구, 9(1), 185-213.

봉진영, 배지희(2012). 다문화 가정 어머니의 자녀 양육 경험에 대한 탐구. 유아교육연구, 32(2), 383-405.

신경, 송원일(2018). 이중언어사용 다문화청소년의 자아정체성 확립 사례연구. 다문화아동청소년연구, 3(2), 99-117.

신윤진, 윤창영(2010). 다문화가정 아동의 이중문화적응, 또래관계 및 이중문화수용간의 관계. 놀이치료연구, 14(2), 1-14.

안종복(2013). 통합교육 환경의 말더듬 학생에 대한 초등학교 교사의 인식 연구. 특수아동교육연구, 15(1),315-333.

여성가족부(2019). 다문화가족지원사업 안내. 서울: 여성가족부.

이경재(2013). 대구지역 교사의 말더듬에 대한 인식. 언어청각장애연구, 18(4), 447-458.

이승숙, 권경숙(2018). 다문화 가정 자녀의 이중언어 관련 연구 동향 분석. 어린이 미디어 연구, 17(1), 299-320.

장유연, 정광순(2012). 초등교사의 다문화 교육에 대한 인식과 실행능력 간의 관계. 초등교육학 연구, 19(1), 91-110. 
정경희, 황상심, 배소영, 김미배(2015). 다문화가족 자녀 언어촉진교육 효과에 관한 질적연구. 언어치료연구, 24(4), 361-378.

정양화(2012). 다문화가족아동의 학업성취도 결정요인 분석. 한국이민학, 3(1), 5-36.

정은희, 유경(2009). 특수교사의 의사소통장애에 대한 인식과 의사소통장애아동의 교육지원 요구 조사. 특수아동교육연구, 11(2), 53-73.

추광재, 최민지(2017). 이중 언어 사용의 특성과 교육 방법에 대한 고찰: 한국 화교(華僑)를 중심으로. 학습자중심교과교육연구, 17(6), 83-105.

탁현주, 김종백, 문경숙(2014). 다문화가정 학생의 한국어 능력과 교사의 다문화 교육 인식이 자기효능감과 학생-교사 애착관계를 매개로 학교적응에

미치는 영향 교육심리연구, 28(1), 23-39.

통계청(2019). 청소년 통계자료. 대전: 통계청.

한국건강가정진흥원(2018). 다문화가족자녀 언어발달지원사업 결과보고서. 서울: 한국건강가정진흥원.

한국청소년상담원(2011). 다문화청소년의 실태 및 개선과제. 서울: 한국청소년상담원.

황상심(2018). 다문화가정의 이중언어 사용에 관한 질적 탐색. 언어치료연구, 27(1), 99-113.

황상심(2019). 다문화아동의 이중언어사용과 교육 서비스 제공에서 통역사 협력에 관한 연구. 언어치료연구, 28(1), 37-46.

황상심, 강복정(2016). 다문화아동의 이중언어사용 추이 연구. 언어치료연구, 25(1), 123-134.

\section{ORCID}

정민지(제1저자, https://orcid.org/0000-0001-5291-4478); 황상심(교신저자, https://orcid.org/0000-0002-7439-583X) 